\title{
Application of Pt/CdS for the Photocatalytic Flue Gas Desulfurization
}

\author{
Xiulan Song, Weifeng Yao, Bo Zhang, and Yiping Wu \\ College of Energy and Environmental Engineering, Shanghai University of Electric Power, 2103 Pingliang Road, \\ Shanghai 200090, China
}

Correspondence should be addressed to Weifeng Yao, yaoweifeng@shiep.edu.cn

Received 12 July 2011; Accepted 29 September 2011

Academic Editor: Jinlong Zhang

Copyright ( 92012 Xiulan Song et al. This is an open access article distributed under the Creative Commons Attribution License, which permits unrestricted use, distribution, and reproduction in any medium, provided the original work is properly cited.

A photocatalytic flue gas desulfurization technology was designed to control emissions of $\mathrm{SO}_{2}$ from the combustion of fossil fuels. With the photocatalytic technology, we cannot only achieve the purpose of solving the problem of $\mathrm{SO}_{2}$ emissions but also realize the desire of hydrogen production from water. CdS loaded with Pt were selected as the model photocatalyst for the photocatalytic flue gas desulfurization. The factors influencing the rate of hydrogen production and ammonia sulfite solution oxidation were detected.

\section{Introduction}

Sulfur oxide $\left(\mathrm{SO}_{2}\right)$ is one of the important air pollutants, which mainly originates from the combustion of coal and fuel derived from petroleum $[1,2]$. In atmosphere, sulfur oxide could combine with oxygen and water resulting in sulfuric acid and may cause serious damage to agriculture and wild life [1]. It is indispensable to find out efficient ways to avoid the $\mathrm{SO}_{2}$ molecules from reaching to the atmosphere. Flue gas desulphurization (FGD) is considered as one of the most effective ways to control emissions of $\mathrm{SO}_{2}$ from the combustion of fossil fuels [3-6]. Among which, ammoniabased wet flue gas desulfurization has drawn increasing attention because of its lower investment, higher desulfurization efficiency, and useful byproducts. The reaction process of the ammonia-based flue gas desulfurization is

$$
\begin{gathered}
2 \mathrm{NH}_{3}+\mathrm{H}_{2} \mathrm{O}+\mathrm{SO}_{2} \longrightarrow\left(\mathrm{NH}_{4}\right)_{2} \mathrm{SO}_{3}, \\
\left(\mathrm{NH}_{4}\right)_{2} \mathrm{SO}_{3}+\mathrm{SO}_{2}+\mathrm{H}_{2} \mathrm{O} \longrightarrow 2 \mathrm{NH}_{4} \mathrm{HSO}_{3}, \\
\mathrm{NH}_{4} \mathrm{HSO}_{3}+\mathrm{NH}_{3} \longrightarrow\left(\mathrm{NH}_{4}\right)_{2} \mathrm{SO}_{3}, \\
2\left(\mathrm{NH}_{4}\right)_{2} \mathrm{SO}_{3}+\mathrm{O}_{2} \longrightarrow 2\left(\mathrm{NH}_{4}\right)_{2} \mathrm{SO}_{4} .
\end{gathered}
$$

The process of ammonia sulfite oxidation (Function (4)) always decides the prospect of applying ammonia-based flue gas desulfurization technology, because high temperature and special instruments are needed to completely oxidize ammonia sulfite. It is of interest if we could find new ways to reduce the expense of ammonia sulfite oxidization.

Semiconductor photocatalysis is one of the hopeful ways to solve current environment and energy problem using the abundant solar light $[7,8]$. It can decompose harmful organic and inorganic pollutants present in air and aqueous solution and can also split water to produce clean and recyclable hydrogen energy. Up to now, a lot of photocatalysts, such as $\mathrm{TiO}_{2}$ [9], CdS [10], $\mathrm{Ag}_{3} \mathrm{PO}_{4}$ [11], AgCl [12, 13], $\mathrm{Bi}_{12} \mathrm{TiO}_{20}$ [14], have been prepared and demonstrated to be able to produce hydrogen and decompose pollution under $\mathrm{UV}$ or visible light irradiation. CdS is known as one of the efficient photocatalysts for hydrogen production under visible light irradiation with sodium sulfite and sodium sulfide as the sacrificial materials.

In this paper, a photocatalytic process combined with ammonia-water method was developed for flue gas desulfurization. It should point out that with the photocatalytic technology, we cannot only achieve the purpose of solving the problem of $\mathrm{SO}_{2}$ emissions but also realize the desire of hydrogen production from water. The chemical reaction of the photocatalytic process can be written as

$$
\left(\mathrm{NH}_{4}\right)_{2} \mathrm{SO}_{3}+\mathrm{H}_{2} \mathrm{O} \stackrel{\text { photocatalyst, light }}{\longrightarrow}\left(\mathrm{NH}_{4}\right)_{2} \mathrm{SO}_{4}+\mathrm{H}_{2} \text {. }
$$

The factors influencing the rate of hydrogen production and ammonia sulfite solution oxidation were detected. 


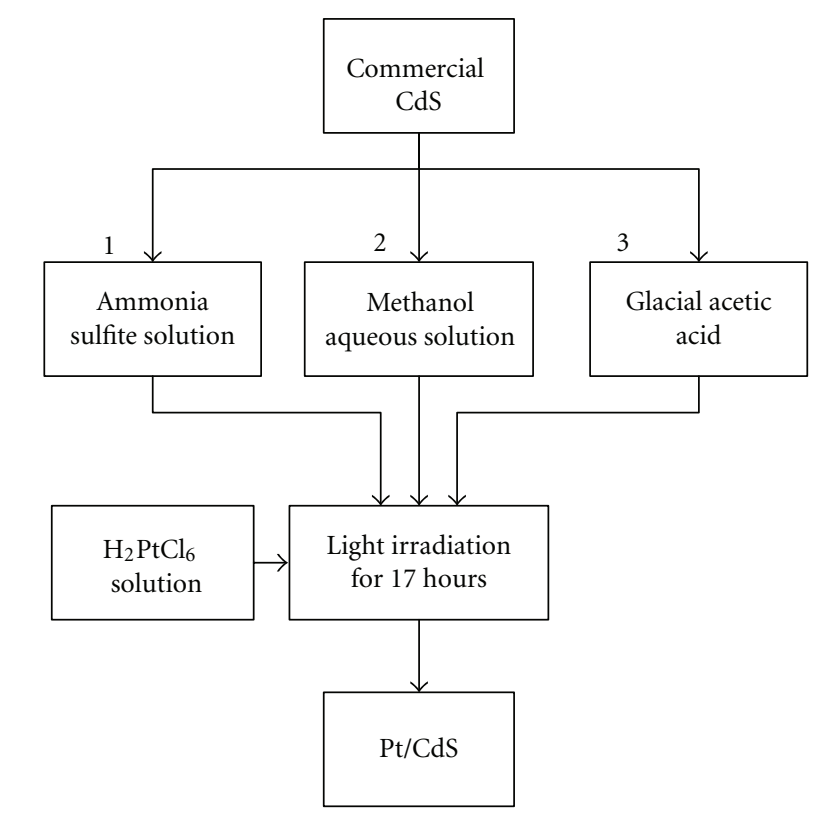

Scheme 1: Schematic procedure of the Pt/CdS catalysts preparation.

\section{Experimental}

2.1. Preparation of Pt/CdS Catalysts. The CdS powder was obtained commercially and used without further purification. Pt was loaded on CdS by using a photoreduction method. The procedure of three catalysts' preparation methods is shown in Scheme 1. CdS was dispersed in $\left(\mathrm{NH}_{4}\right)_{2} \mathrm{SO}_{3}$ $\left(\mathrm{CH}_{3} \mathrm{OH}\right.$ or glacial acetic acid) solution containing different amount of $\mathrm{H}_{2} \mathrm{PtCl}_{6}$. The mixture was then exhausted and irradiated with $350 \mathrm{~nm} \sim 800 \mathrm{~nm}$ light for $17 \mathrm{~h}$. The resulting $\mathrm{Pt} / \mathrm{CdS}$ powder was collected, washed, and then dried at $333 \mathrm{~K}$ for $4 \mathrm{~h}$.

2.2. Photocatalytic Reaction. The photocatalytic reactions were carried out in a Pyrex reaction cell connected to a closed gas circulation and evacuation system. Certain amount of the prepared $\mathrm{Pt} / \mathrm{CdS}$, for example, $0.05 \mathrm{~g}$, was suspended in $100 \mathrm{~mL}$ of $\left(\mathrm{NH}_{4}\right)_{2} \mathrm{SO}_{3}$ aqueous solution. The solution was then thoroughly degassed and irradiated by a Xe lamp equipped with an optical cutoff filter $(\lambda>420 \mathrm{~nm})$ to eliminate UV light and a water filter to remove infrared light. The amounts of $\mathrm{H}_{2}$ evolved were detected using an online gas chromatography.

\section{Results and Discussion}

3.1. Photocatalytic Oxidation of Ammonia Sulfite. The rate of $\mathrm{H}_{2}$ production and ammonia sulfite oxidation over $\mathrm{Pt} / \mathrm{CdS}$ photocatalysts is very high. Figure 1 shows a typical result of the photocatalytic $\mathrm{H}_{2}$ production from ammonia sulfite solution with simulated sunlight $(350 \sim 800 \mathrm{~nm})$ irradiation. It is noted that hydrogen was generated continuously from the ammonia sulfite solution and the rate of hydrogen production has no decreases after an 8-hour reaction. The amount of $\mathrm{H}_{2}$ generated in the reaction $(6.44 \mathrm{mmol})$ was

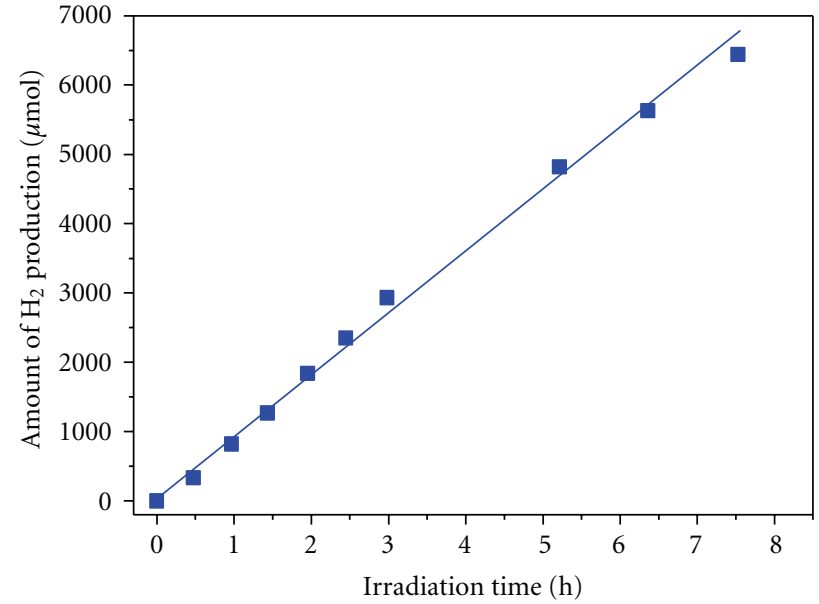

Figure 1: Photocatalytic hydrogen production from aqueous ammonia sulfite solution. Catalyst: $0.05 \mathrm{~g} \mathrm{Pt} / \mathrm{CdS} ; 100 \mathrm{~mL} 1.25 \mathrm{M}$ $\left(\mathrm{NH}_{4}\right)_{2} \mathrm{SO}_{3}$; incident light: (350 800 nm).

much greater than that of CdS $(0.35 \mathrm{mmol})$ used in the reaction, indicating that the reaction of hydrogen production from the ammonia sulfite solution over Pt/CdS photocatalysts is a photocatalytic process but not a photocorrosion process.

Couple with hydrogen production, the ammonia sulfite was oxidized to ammonia sulfate by the photocatalytic reactions. The production of ammonia sulfate was confirmed by using the ion chromatography (IC), which shows that the amount of sulfate ions in the solution increases but sulfite ions decrease linearly in the process of the photocatalytic reactions. It should point out that the sulfite ions were finally completely oxidized to sulfate after a long-term photocatalytic reaction (about $120 \mathrm{~h}$ ). This result indicates that 


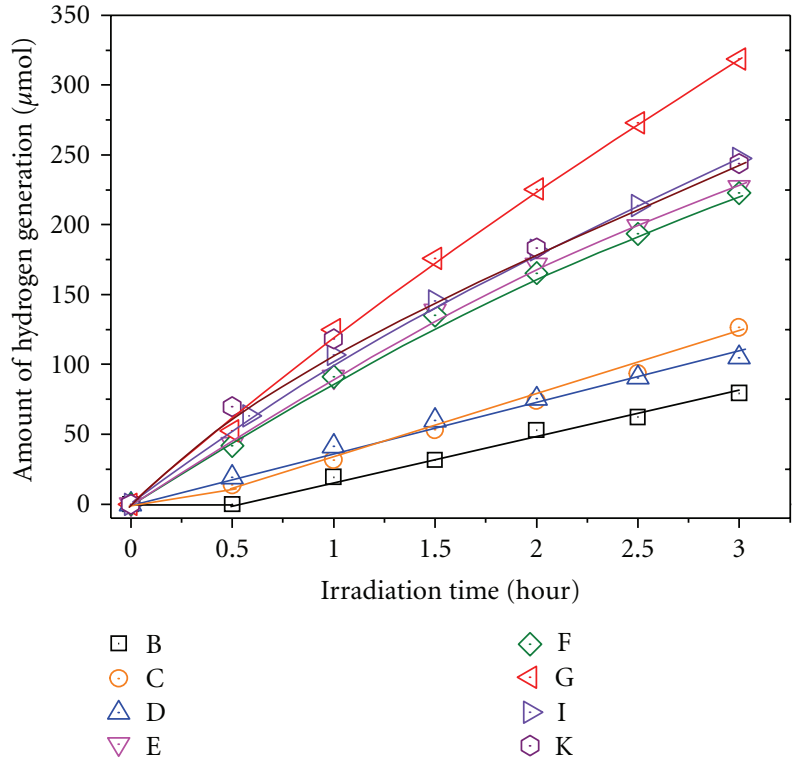

(a)

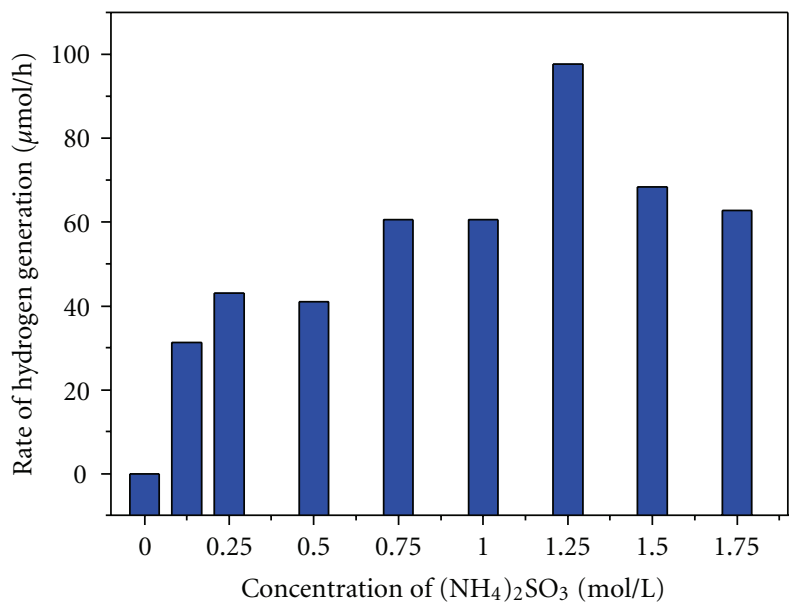

(b)

FIGURE 2: Influence of $\left(\mathrm{NH}_{4}\right)_{2} \mathrm{SO}_{3}$ concentration on photocatalytic activity. $\left(\mathrm{NH}_{4}\right)_{2} \mathrm{SO}_{3}$ concentration: (B) $0.125 \mathrm{M}$; (C) $0.25 \mathrm{M}$; (D) $0.5 \mathrm{M}$; (E) $0.75 \mathrm{M}$; (F) $1 \mathrm{M}$; (G) $1.25 \mathrm{M}$; (I) $1.5 \mathrm{M}$; (K) $1.75 \mathrm{M}$; incident light (420 800 nm).

the oxidation of ammonia sulfite, which is a key problem of an ammonia-based wet flue gas desulfurization process, could be efficiently operated by using the technology of photocatalysis.

\subsection{Influence of the Ammonia Sulfite Concentration on Hydro-} gen Generation. The influence of the ammonia sulfite concentration on the rate of hydrogen formation was measured for the oxidation reactions of sulfite ions. As shown in Figure 2, hydrogen evolution is very sensitive to the concentration of ammonia sulfite. The rate of hydrogen production from a $1.25 \mathrm{M}$ ammonia sulfite solution was almost 4 times higher than that from $0.125 \mathrm{M}$ ammonia sulfite solution. For a photocatalytic reaction, the increase of reactant concentration normally favors a forward reaction, because a high reactant concentration could be expected for the diffusion of the reacting species to and from the surface of the photocatalysts [10]. However, as shown in Figure 2, the hydrogen evolution rate declined when the ammonia sulfite's concentration is higher than 1.25 M. A similar loss of activity of hydrogen production at high $\mathrm{Na}_{2} \mathrm{SO}_{3}$ concentrations has been observed by Reber and Meier [15] and Aruga et al. [16] when using ZnS and CdS as the photocatalysts.

This phenomenon is attributed to the higher solution viscosity and lower ionic transport ability of the higher electrolyte concentration [17], which may increase the electronhole recombination [15] and make hydrogen bubbles formed on the surface of photocatalyst more difficult to be released. The optimal electrolyte concentration reported by Reber and Meier $(1.0 \mathrm{M})$ is in agreement with our data [15].

3.3. Influence of Platinum Coating Amounts on Hydrogen Generation. Noble metals such as $\mathrm{Pt}, \mathrm{Pd}, \mathrm{Ru}$, and $\mathrm{Rh}$ function as efficient $\mathrm{H}_{2}$ evolution promoters for many photocatalysts [18-21]. Among which, Pt is usually the best promoter for $\mathrm{H}_{2}$ evolution, which has a superior performance for the activation of $\mathrm{H}_{2}$ in the electrochemical system. The influence of the platinum coating at the surface of the CdS particles on the rate of hydrogen production and ammonia sulfite oxidation at the present experimental condition was detected. It is noted that noble metal Pt loading plays an important role on hydrogen evolution from ammonia sulfite solution. The photocatalytic activity of pure CdS for hydrogen evolution is very low, as shown in Figure 3, the rate of hydrogen production over CdS photocatalysts was only about $7 \mu \mathrm{mol} / \mathrm{h}$ under visible light irradiation (larger than $420 \mathrm{~nm}$ ). However, when $0.5 \mathrm{wt} \% \mathrm{Pt}$ was deposited on CdS, the $\mathrm{H}_{2}$ evolution rate quickly increased to $62 \mu \mathrm{mol} / \mathrm{h}$. The optimum amount of $\mathrm{Pt}$ loading appeared to be about $0.7 \mathrm{wt} \%$ yielding a maximum rate of hydrogen production, $97.7 \mu \mathrm{mol} / \mathrm{min}$, under visible light irradiation.

For the photocatalytic reactions, especially for the oxidation of $\mathrm{SO}_{3}{ }^{2-}$ ions, the $\mathrm{Pt}$ fraction at the surface of the photocatalysts has been reported must be relatively high (larger than $0.5 \mathrm{wt} \%$ ) to produce an acceptable activity. Whereas, an increasing amount of platinum loading is believed to result in an increasing fraction of dissolved CdS [10], which would be harmful for the catalysts to show a high activity. Note that by increasing the Pt loading to $0.8 \mathrm{wt} \%$, the rate of hydrogen production dropped somewhat to about $85.3 \mu \mathrm{mol} / \mathrm{h}$, under visible light irradiation (Figure 3 ).

\subsection{Influence of the Amount of Cadmium Sulfide on Hydrogen} Generation. Figure 4 shows the influence of CdS amount on the photocatalytic activity of hydrogen production from ammonia sulfite solution. In this experiment, a $1.25 \mathrm{M}$ and 


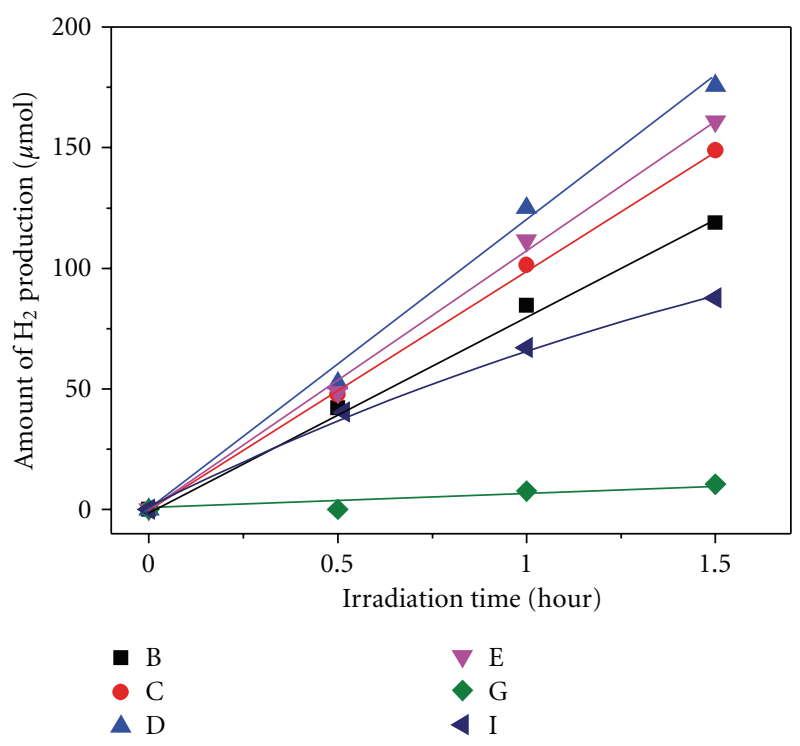

(a)

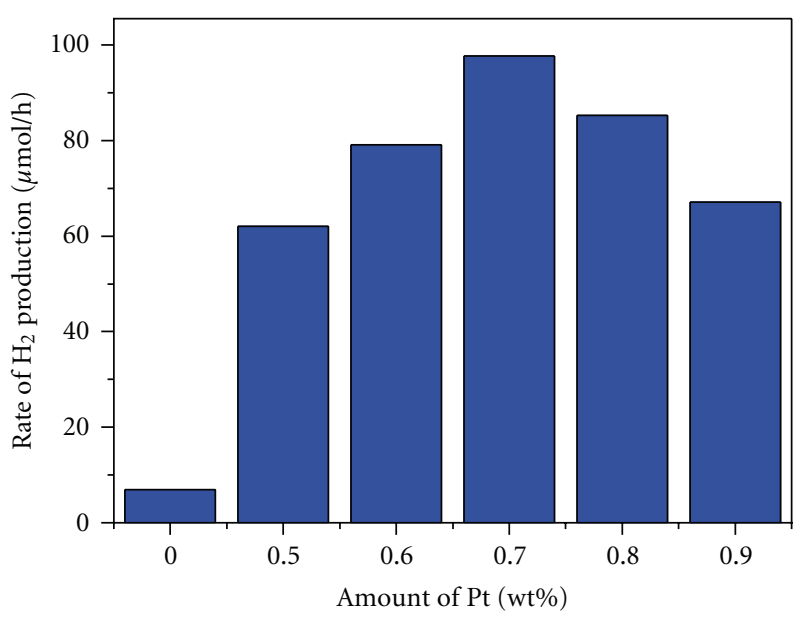

(b)

FIGURE 3: Influence of platinum coating amounts (Pt versus CdS) on hydrogen generation. (B) Pure phase of CdS; (C) 0.5 wt. \%; (D) 0.6 wt \%; (E) $0.7 \mathrm{wt} \%$; (G) $0.8 \mathrm{wt} \%$; (I) $0.9 \mathrm{wt} \%$. incident light: $420 \sim 800 \mathrm{~nm}$.

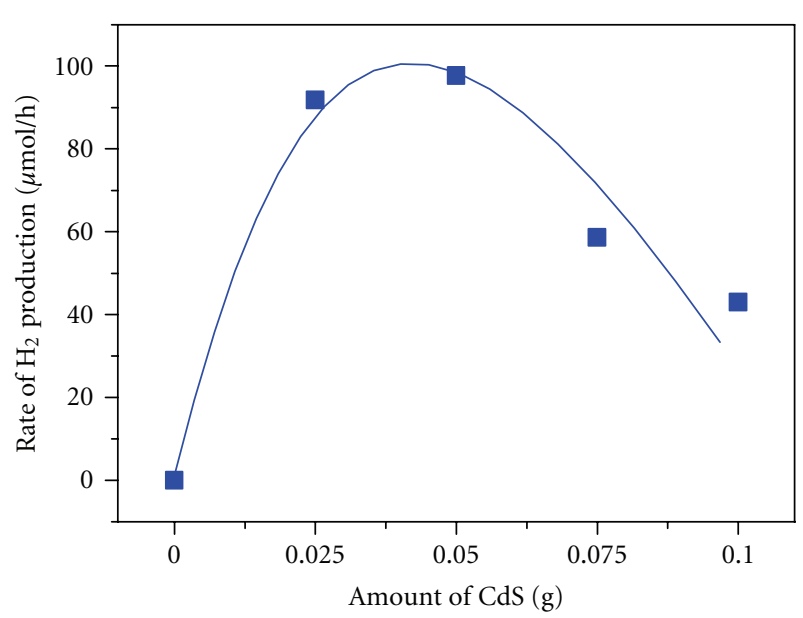

FIGURE 4: Influence of the amount of cadmium sulfide on hydrogen generation.

$100 \mathrm{~mL}$ aqueous ammonium sulfite solution was used as photolyte and $0.7 \mathrm{wt} \%$ of $\mathrm{Pt}$ was loaded on CdS for the photocatalytic hydrogen production. The result shows that the optimal amount of catalyst for hydrogen production was $0.05 \mathrm{~g}$. Normally, more photocatalysts favor to absorb more incidents light and would provide more active sites for hydrogen evolution. However, when more CdS particles were suspended in the solution, the light scattering effect is enhanced. This would cause the photonic energy loss and decrease the photocatalytic activity. As shown in Figure 4, the activity of hydrogen production is declined when the catalyst's amount was higher than $0.05 \mathrm{~g}$.

\subsection{Influence of Pt Coating Method on Hydrogen Generation.}

Figure 5 shows the influence of Pt coating method on the

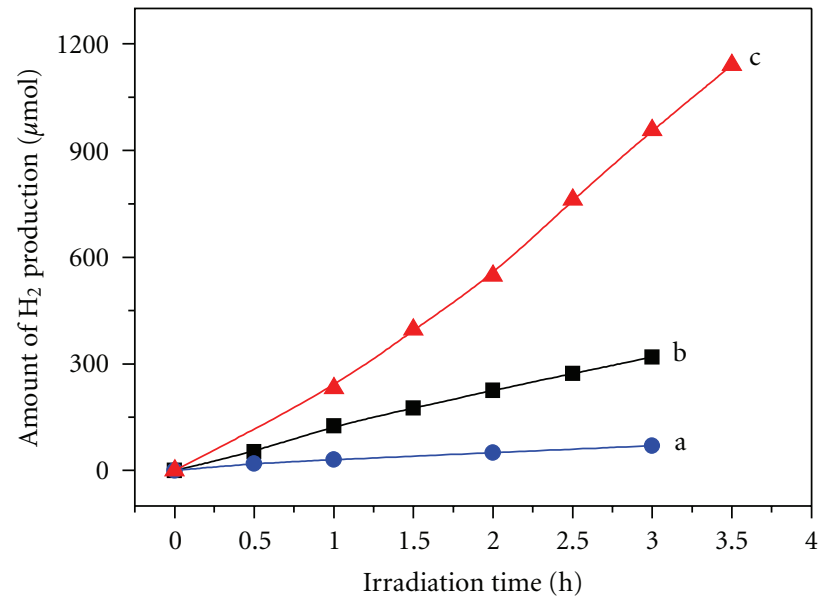

FIGURE 5: Influence of Pt coating method on hydrogen generation. (a) $\mathrm{Pt} / \mathrm{CdS}$ (Sample 1) prepared from a methanol solution; (b) $\mathrm{Pt} / \mathrm{CdS}$ (Sample 2) prepared from an ammonia sulfite solution; (c) $\mathrm{Pt} / \mathrm{CdS}$ (Sample 3) prepared from a glacial acetic acid.

photocatalytic activity of $\mathrm{Pt} / \mathrm{CdS}$ for hydrogen production and ammonia sulfite oxidation. Three differently prepared samples of $\mathrm{Pt} / \mathrm{CdS}$ were illuminated in the ammonia sulfite solution under visible light irradiation. It is apparent that hydrogen is generated in all the cases when the catalysts were illuminated. However, the activity of these catalysts for hydrogen production is strongly dependent on the preparation method of $\mathrm{Pt} / \mathrm{CdS}$ catalysts. It is noted that Sample 1 , which was prepared from a methanol solution, showed a much low activity for hydrogen production from ammonia sulfite solution. Only $70 \mu \mathrm{mol} \mathrm{H}_{2}$ was produced from ammonia sulfite solution within 3 hours under visible light irradiation (Line a, Figure 5). In contrast, $330 \mu \mathrm{mol} \mathrm{H}_{2}$ was 
obtained over Sample 2 prepared from ammonia sulfite solution (Line b, Figure 5) under the same condition. The highest rate was observed by illuminating the Sample 3, which was prepared from the glacial acetic acid. It is noted that $950 \mu \mathrm{mol} \mathrm{H} \mathrm{H}_{2}$ was evolved from ammonia sulfite solution within 3 hours under the present working condition (Line c, Figure 5). The high activity of the Pt/CdS samples, prepared from the glacial acetic acid, for hydrogen production and ammonia sulfite oxidation is not clear. The process of treatment in acetic acid is thought helpful for the elimination of CdO fraction, which is lying at the CdS surface and harmful for the photocatalytic reactions [10, 22]. Further works, such as detection of the ingredient, valence state, particle size of Pt over CdS, are still under way to determine the mechanism of the different activities of the three samples prepared with different methods.

\section{Conclusion}

In summary, the oxidation of ammonia sulfite, which is a key problem of an ammonia-based wet flue gas desulfurization process, could be efficiently operated by using the technology of photocatalysis. With the photocatalytic technology, we cannot only achieve the purpose of solving the problem of $\mathrm{SO}_{2}$ emissions but also realize the desire of hydrogen production from water. The photocatalytic activity for hydrogen production and ammonia sulfite oxidation was found strongly dependent on $\left(\mathrm{NH}_{4}\right)_{2} \mathrm{SO}_{3}$ concentration, amount of $\mathrm{Pt} / \mathrm{CdS}$ catalyst, and Pt coating method.

\section{Acknowledgments}

This work was financially supported by the National Natural Science Foundation of China (21103106), Shanghai RisingStar Program (10QA1402800), Shanghai Nano Special Foundation (1052nm02600), Construction Capacity Project (10160502300) and (09230501400). W. Yao thanks the fund of Specially-Appointed Professors (Oriental Scholars) for Shanghai Universities.

\section{References}

[1] A. C. Stern, R. W. Boubel, D. B. Turner, and D. L. Fox, Fundamentals of Air Pollution, Academic Press, Orlando, Fla, USA, 2nd edition, 1984.

[2] A. V. Slack and G. A. Hollinden, Sulfur Dioxide RemoVal from Waste Gases, Noyes Data Corporation, Park Ridge, NJ, USA, 2nd edition, 1975.

[3] B. B. Hansen, S. Kiil, J. E. Johnsson, and K. B. Sønder, "Foaming in wet flue gas desulfurization plants: the influence of particles, electrolytes, and buffers," Industrial and Engineering Chemistry Research, vol. 47, no. 9, pp. 3239-3246, 2008.

[4] X. Ma, T. Kaneko, T. Tashimo, T. Yoshida, and K. Kato, "Use of limestone for $\mathrm{SO}_{2}$ removal from flue gas in the semidry FGD process with a powder-particle spouted bed," Chemical Engineering Science, vol. 55, no. 20, pp. 4643-4652, 2000.

[5] G. Astarita, D. W. Savage, and A. Bisio, Gas Treating with Chemical Solvents, Wiley-Interscience, New York, NY, USA, 1983.
[6] H. F. Johnstone, "Recovery of Sulfur Dioxide from Waste Gases," Industrial \& Engineering Chemistry Research, vol. 32, no. 8, pp. 1037-1049, 1940.

[7] X. Chen, S. Shen, L. Guo, and S. Mao, "Semiconductor-based photocatalytic hydrogen generation," Chemical Reviews, vol. 110, no. 11, pp. 6503-6570, 2010.

[8] S. Shen, J. Shi, P. Guo, and L. Guo, "Visible-light-driven photocatalytic water splitting on nanostructured semiconducting materials," International Journal of Nanotechnology, vol. 8, no. 6-7, pp. 523-591, 2011.

[9] A. Fujishima and K. Honda, "Electrochemical photolysis of water at a semiconductor electrode," Nature, vol. 238, no. 5358, pp. 37-38, 1972.

[10] N. Bühler, K. Meier, and J. F. Reber, "Photochemical hydrogen production with cadmium sulfide suspensions," Journal of Physical Chemistry, vol. 88, no. 15, pp. 3261-3268, 1984.

[11] Z. Yi, J. Ye, N. Kikugawa et al., "An orthophosphate semiconductor with photooxidation properties under visible-light irradiation," Nature Materials, vol. 9, no. 7, pp. 559-564, 2010.

[12] P. Wang, B. Huang, X. Qin et al., "Ag@AgCl: a highly efficient and stable photocatalyst active under visible light," Angewandte Chemie, vol. 47, no. 41, pp. 7931-7933, 2008.

[13] P. Wang, B. Huang, Z. Lou et al., "Synthesis of highly efficient Ag@AgCl plasmonic photocatalysts with various structures," Chemistry, vol. 16, no. 2, pp. 538-544, 2010.

[14] W. Yao, H. Wang, X. H. Xu et al., "Photocatalytic property of bismuth titanate $\mathrm{Bi}_{12} \mathrm{TiO}_{20}$ crystals," Applied Catalysis A, vol. 243, no. 1, pp. 185-190, 2003.

[15] J. F. Reber and K. Meier, "Photochemical production of hydrogen with zinc sulfide suspensions," Journal of Physical Chemistry, vol. 88, no. 24, pp. 5903-5913, 1984.

[16] T. Aruga, K. Domen, S. Naito, T. Onishi, and K. Tamaru, "The role of sulfite anion as a hole scavenger in the photocatalytic hydrogen formation from water under illumination of visible light," Chemistry Letters, vol. 7, pp. 1037-1040, 1983.

[17] R. de Souza, J. Padilha, R. Gonçalves, and J. Rault-Berthelot, "Dialkylimidazolium ionic liquids as electrolytes for hydrogen production from water electrolysis," Electrochemistry Communications, vol. 8, no. 2, pp. 211-216, 2006.

[18] H. Kato, K. Asakura, and A. Kudo, "Highly efficient water splitting into $\mathrm{H}_{2}$ and $\mathrm{O}_{2}$ over lanthanum-doped $\mathrm{NaTaO}_{3}$ photocatalysts with high crystallinity and surface nanostructure," Journal of the American Chemical Society, vol. 125, no. 10, pp. 3082-3089, 2003.

[19] X. Zong, H. Yan, G. Wu et al., "Enhancement of photocatalytic $\mathrm{H}_{2}$ evolution on CdS by loading $\mathrm{MoS}_{2}$ as cocatalyst under visible light irradiation," Journal of the American Chemical Society, vol. 130, no. 23, pp. 7176-7177, 2008.

[20] W. Yao, C. Huang, N. Muradov, and A. T-Raissi, "A novel $\mathrm{Pd}-\mathrm{Cr}_{2} \mathrm{O}_{3} / \mathrm{CdS}$ photocatalyst for solar hydrogen production using a regenerable sacrificial donor," International Journal of Hydrogen Energy, vol. 36, no. 8, pp. 4710-4715, 2011.

[21] W. Yao, C. Huango, and J. Ye, "Hydrogen production and characterization of $\mathrm{MLaSrNb}_{2} \mathrm{NiO}_{9}(\mathrm{M}=\mathrm{Na}, \mathrm{Cs}, \mathrm{H})$ based photocatalysts," Chemistry of Materials, vol. 22, no. 3, pp. 1107-1113, 2010.

[22] M. Matsumura, S. Furukawa, Y. Saho, and H. Tsubomura, "Cadmium sulfide photocatalyzed hydrogen production from aqueous solutions of sulfite: effect of crystal structure and preparation method of the catalyst," Journal of Physical Chemistry, vol. 89, no. 8, pp. 1327-1329, 1985. 


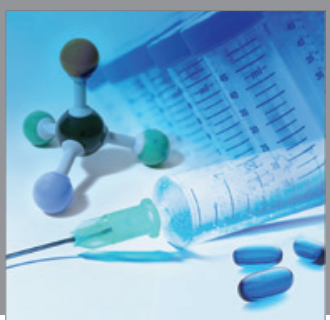

International Journal of

Medicinal Chemistry

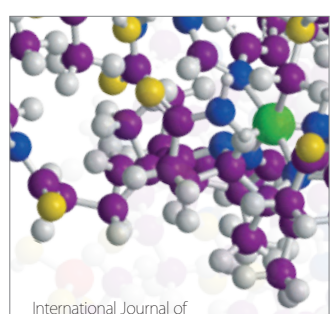

Carbohydrate Chemistry

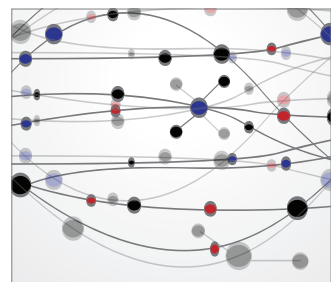

The Scientific World Journal
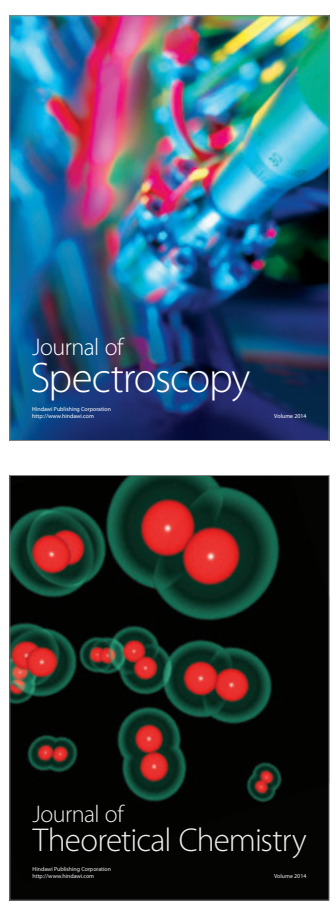
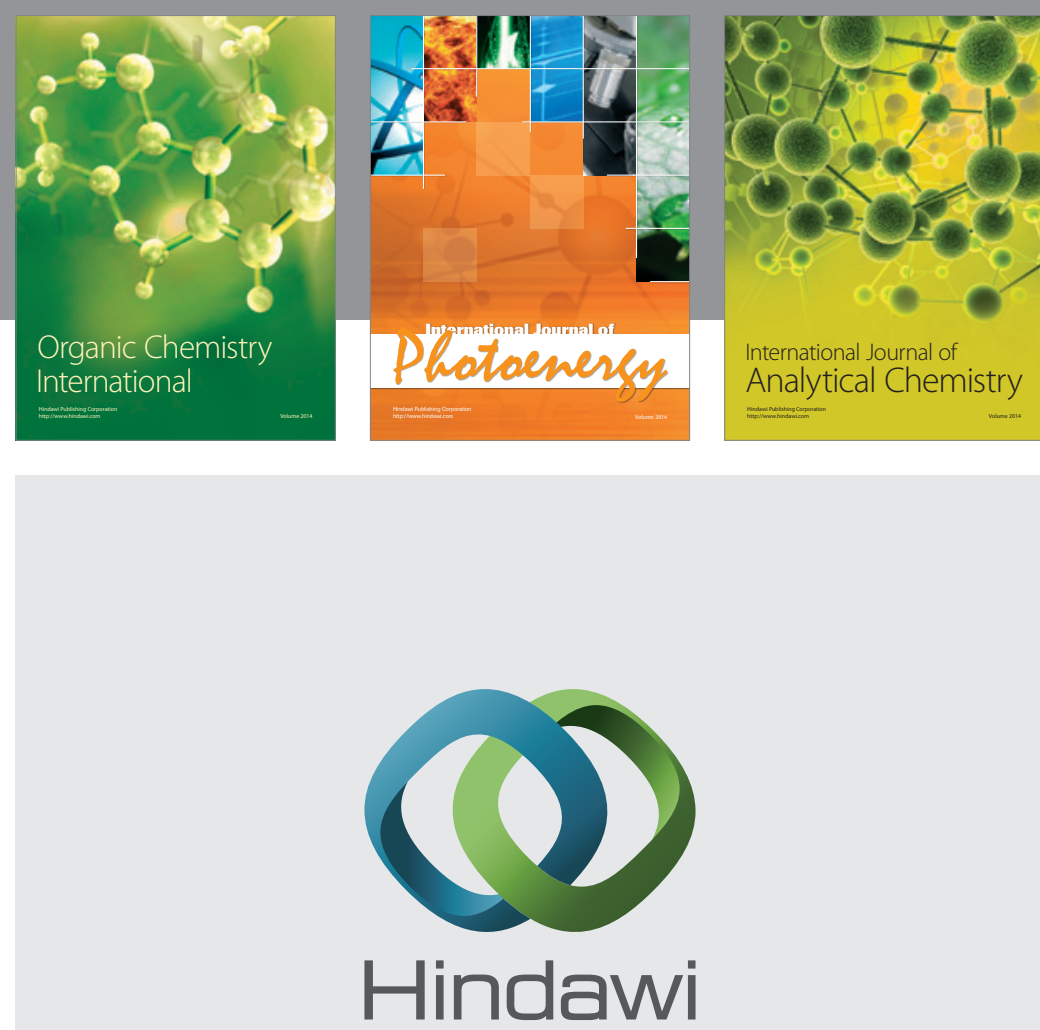

Submit your manuscripts at

http://www.hindawi.com
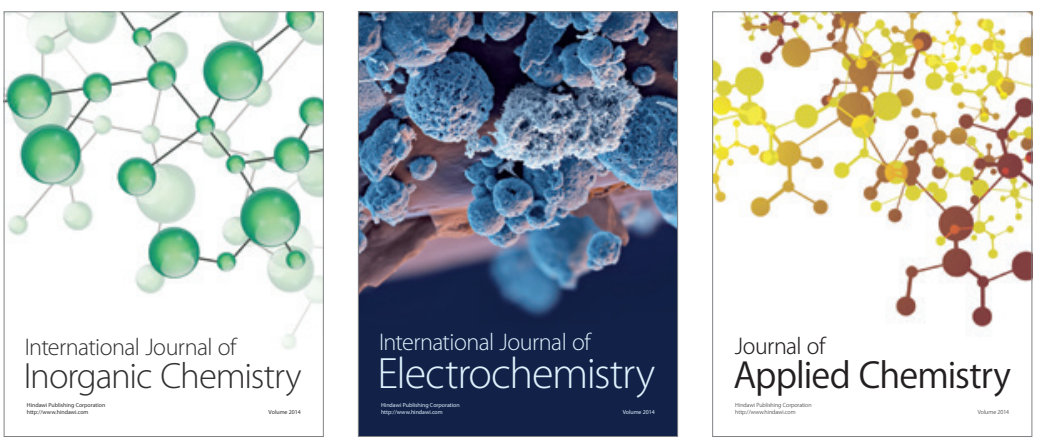

Journal of

Applied Chemistry
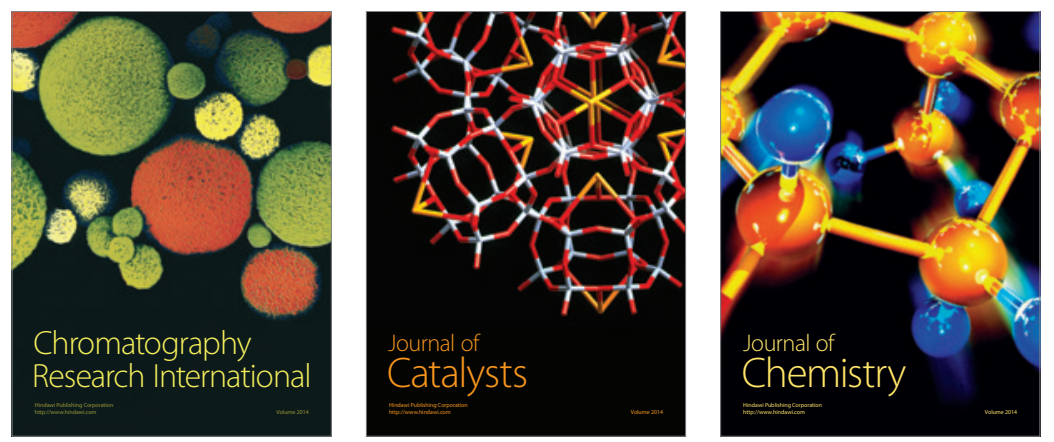
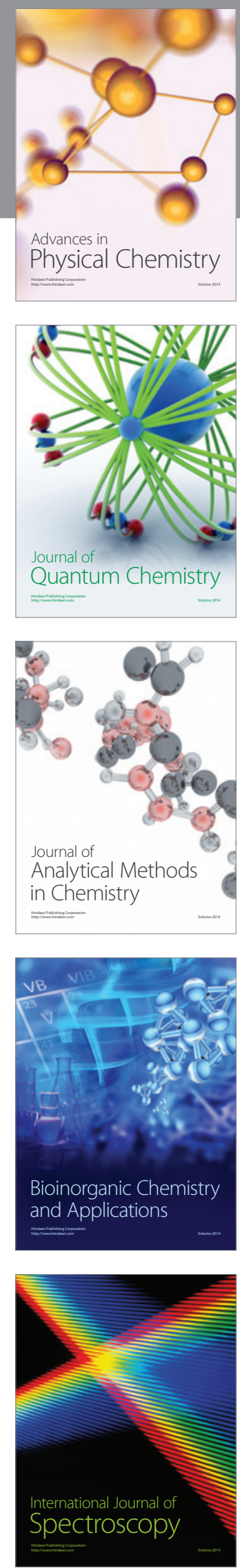